\title{
Escolhas Possíveis: narrativas de estudantes universitários
}

\author{
Renata Mourão Macedo' \\ 'Universidade de São Paulo (USP), São Paulo/SP - Brasil
}

RESUMO - Escolhas Possíveis: narrativas de estudantes universitários ${ }^{1}$. A partir de pesquisa etnográfica realizada na cidade de São Paulo (SP), o artigo aborda a temática das escolhas educacionais no ensino superior. São analisadas as narrativas de quatro estudantes universitários, focalizando três processos de escolhas: a escolha por fazer ensino superior, por determinado curso e por uma instituição de ensino. O objetivo é mostrar as negociações de sentido realizadas pelos estudantes, constituindo escolhas possiveis. Como pano de fundo, está a argumentação de que a conjuntura de expansão do ensino superior nos anos 2000 e 2010 - em suas ambivalências e contradições - permitiu que tais escolhas entrassem no campo de possibilidades de novos agentes, a saber, de estudantes que são a primeira geração da família a cursar ensino superior.

Palavras-chave: Ensino Superior. Estudantes. Escolha Profissional. Marcadores Sociais da Diferença.

ABSTRACT - Possible Choices: narratives of university students. Based on an ethnographic research carried out in the city of São Paulo (SP), the article addresses the issue of educational choices in higher education. The narratives of four university students are analyzed, focusing on three processes of choices among students - the decision to enter in higher education, the choice of the course and the institution. The purpose of the article is to show the negotiations carried out by the students, constituting possible choices. As a background, is the argument that the conjuncture of expansion of higher education in the 2000s and 2010 - in its ambivalences and contradictions - allowed such choices to enter the field of possibilities for new agents, namely, students who are the first generation of the family to attend higher education.

Keywords: Higher Education. Students. Professional Choice. Social Markers of Difference.

Educação \& Realidade, Porto Alegre, v. 46, n. 3, e105800, 2021. 


\title{
Introdução
}

\begin{abstract}
Chegou o grande momento! Você, provavelmente, está no final do Ensino Médio ou no cursinho e, depois de pensar muito, enfim, terá que tomar a primeira grande decisão da sua vida. E uma dúvida que sempre aparece nessa hora é: 'será que eu fiz a escolha certa?' (ABRIL, Guia do Estudante, 2016, p. 14)
\end{abstract}

Assim se inicia a primeira reportagem do Guia do Estudante de 2016, publicação voltada para orientar estudantes no processo de escolha do curso superior ${ }^{2}$. Direcionado para um público de jovens de classes médias e altas, que percebem a transição do ensino médio para o ensino superior como um processo natural de suas trajetórias, a reportagem define esse momento de escolha como "[...] a primeira grande decisão da sua vida". Para auxiliar nesse processo, o texto propõe um mapa do autoconhecimento: "[...] ninguém se conhece de verdade sem uma análise sincera de sua personalidade". Sugere, nesse sentido, sete pontos para reflexão, entre eles, quais são suas características pessoais e o que você pretende ser quando crescer?.

Além do Guia do Estudante, diversas publicações online oferecem auxílio para milhões de estudantes pré-universitárias/os em dúvida sobre vestibulares, cursos e instituições de ensino superior (IES) ${ }^{3}$. Acompanhar o ritmo de tais publicações é tarefa árdua: a cada ano multiplicam-se os testes vocacionais, os rankings educacionais, as opiniões de especialistas, além das feiras promovidas por diferentes instituições ligadas à educação, como a Feira do Guia do Estudante e a Feira do Estudante do Centro de Integração Empresa-Escola (Expo CIEE), para ficar apenas em alguns dos eventos privados realizados na cidade de São Paulo. Em toda essa produção discursiva promovida por tais publicações e eventos, a famosa questão o que você vai ser quando crescer? (imagem 1) é repetida diversas vezes, revelando ser essa uma das questões centrais, ainda que ingênua, para orientar o processo de formação de adultos produtivos e realizados nas sociedades contemporâneas estratificadas.

\section{Imagem 1 - Feira Guia do Estudante, Pavilhão de Exposições do Anhembi, 2017 - São Paulo}

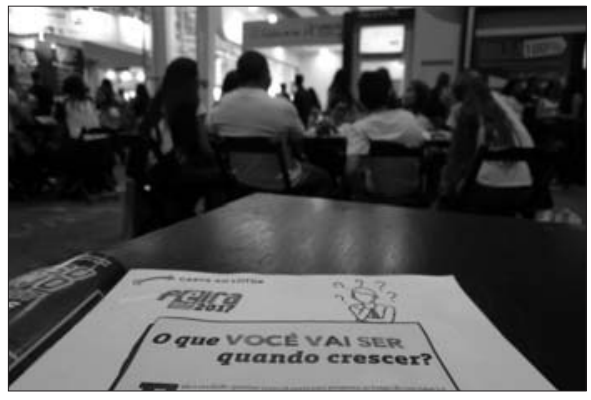

Fonte: fotografia da autora. 
Para dimensionar essa sensação de excesso que senti ao pesquisar esse universo discursivo, vale lembrar que, tomando o Guia do Estudante como referência, na edição de 2018 foram listados 280 cursos de ensino superior diferentes ${ }^{4}$, incluindo desde as chamadas profissões imperiais brasileiras - Medicina, Engenharia e Direito (Vargas, 2010) -, até as novíssimas carreiras, como Design, Estética e Gastronomia (Sampaio, 2014). Para além da escolha do curso, o estudante pré-universitário deve também equacionar a escolha da instituição, com todas suas variáveis (se pública ou privada; se o ingresso se dará pelo ENEM ${ }^{5}$ ou outros vestibulares concorridos; se a instituição de ensino será próxima da residência do estudante ou em outra cidade; no caso de instituição privada, quais serão os preços da mensalidade, oferta de bolsas, descontos etc.). De fato, diante de um mercado diferenciado de ensino superior, são muitas as opções de cursos e instituições em uma grande cidade como São Paulo.

No entanto, para além desse estudante ideal, imaginado por tais publicações e eventos - jovem, finalizando o Ensino Médio, com uma trajetória escolar que lhe permita escolher com autonomia entre tantos cursos e universidades -, o espaço educacional brasileiro recente apresenta perfis universitários bastante diversos, marcados desigualmente por marcadores sociais da diferença como gênero, classe social, geração e raça ${ }^{6}$. No entanto, o discurso da escolha individual e livre, exclusivamente voltada aos dons individuais, ainda impera em parcela importante da área de orientação vocacional e coaching, além das publicações e eventos do setor.

Ao conversar com os estudantes universitários que participaram da pesquisa apresentada neste artigo, contudo, novas questões se colocaram: os processos de escolhas para ingresso nos estudos superiores são similares para perfis diversos de estudantes? Conforme veremos a seguir, tento demonstrar neste artigo que sim e que não. De um lado, o peso da escolha, conforme expressão da antropóloga Margaret Mead $(1973)^{7}$, consterna a todos, trazendo dúvidas, angústias e dilemas entre diferentes perfis de estudantes. No entanto, experiências sociais diversas, marcadas por gênero, situação de classe, trajetória escolar, idade, maternidade e religião, entre outras variáveis, impõem especificidades que devem ser levadas em conta na análise. Mulheres enfrentam os mesmos desafios na escolha dos estudos superiores que homens? As jovens se deparam com os mesmos dilemas que mulheres mais velhas com filhos? De que modo marcadores sociais da diferença como classe e raça impactam tais escolhas em um país fortemente estratificado como o Brasil?

A própria noção de escolhas, nesse sentido, merece ser questionada. Conforme pontuou Maria da Graça Setton (2016, p. 65) ao também refletir sobre escolhas educacionais, “[...] a palavra escolha é, por vezes, traiçoeira", permitindo significados muito diversos. Por um lado, remete à liberdade, por outro, a constrangimentos. Pensada criticamente como constitutiva do indivíduo consumidor na cultura de iniciativa (enterprise culture), de acordo com a expressão provocativa de Strathern 
(1991), ou sempre com aspas, já que estruturalmente determinada, como propõe Bourdieu (1998), a noção de escolhas envolve, de fato, muitas armadilhas. Ainda assim, ao ser reivindicada nas narrativas dos estudantes apresentados neste artigo como um direito só recentemente conquistado, é que a noção de escolhas é aqui mobilizada.

Visando apreender tais sentidos ambivalentes e instáveis, aproximo-me da proposta de Claudio Nogueira (2012) de reflexão sobre o processo de escolha dos estudos superiores, que envolveria uma série de matizes analíticos: de um lado, a importância de se levar em conta gostos e preferências individuais, expectativas e projetos de vida, informações sobre o sistema universitário e o mercado de trabalho; de outro lado, as configurações em termos de classe social, gênero, raça e geração dadas pela posição social, muitas vezes imperceptíveis ao sujeito, que condicionariam o acesso às posições mais privilegiadas do sistema educacional.

Assim, o objetivo deste artigo é evidenciar narrativas sobre dilemas nos processos de escolha nos estudos superiores, apontando para as negociações de escolhas possíveis. Visando me aproximar de tais questões, acompanho as narrativas de quatro estudantes universitários que optaram por buscar qualificação e mobilidade social cursando o ensino superior na cidade de São Paulo, os quais foram acompanhados por meio de pesquisa etnográfica. Em paralelo, aponto para algumas questões mais amplas sobre a configuração atual do ensino superior brasileiro em relação aos marcadores sociais da diferença. O objetivo, assim, é inserir tais narrativas em uma configuração mais ampla, levando em conta projetos individuais e o campo de possibilidades em transformação (Velho, 2013) ${ }^{8}$.

\section{Pesquisa de Campo e Perspectivas Teórico-Metodológicas}

Inspirada em trabalhos de cunho mais etnográfico sobre processos educativos realizados na Antropologia e na Sociologia, que trazem um olhar aproximado sobre estudantes e suas negociações cotidianas (Gusmão, 1997; Pereira, 2016; Willis, 1991; Ortner, 2003; Lahire, 1997), a pesquisa de campo apresentada neste artigo foi realizada a partir de conversas e entrevistas com 21 estudantes universitários de duas IES privadas em São Paulo. Foram selecionados três cursos - Enfermagem, Pedagogia e Administração - e duas instituições privadas de ensino superior, que chamei de Faculdade Centro e Faculdade Bairro ${ }^{9}$.

Além da observação participante, realizei entrevistas semiestruturadas com 21 estudantes. A maioria dessas entrevistas foi realizada nos arredores ou nas lanchonetes das duas faculdades. Todas essas entrevistas foram seguidas por conversas informais, tanto de modo presencial quanto online, acompanhando sempre que possível suas experiências universitárias. A troca de contatos via redes sociais foi uma ferramenta fundamental para manter essas interlocuções, conversar, trocar referências, ver fotos sobre familiares e assuntos de interesse, 
além de permitir marcar novos encontros. Entrando em um fluxo contínuo online-offline, que me permitiu seguir pessoas, locais e hashtags, a pesquisa acabou tendo uma inesperada continuidade no universo online (Miskolci, 2016; Lins; Parreiras; Freitas, 2020).

Neste artigo, inspirando-me na perspectiva de retratos, utilizada tanto na pesquisa sobre sucesso e fracasso escolar realizada por Bernard Lahire (1997) como em reflexões metodológicas posteriores do autor (Lahire, 2004), selecionei quatro trajetórias para refletir de maneira mais detida sobre os dilemas envolvidos nos processos de escolhas em relação a diferentes marcadores sociais da diferença. Assim, apresento trechos das narrativas dos estudantes entrevistados, bem como aspectos etnográficos analisados no momento da entrevista e na observação participante. Conforme registra Lahire (2004, p. 35), ao analisar trajetórias individuais por meio de entrevistas em profundidade, trata-se do esforço de "[...] encontrar a heterogeneidade incorporada do indivíduo", atento para a variedade de experiências, contextos, contradições e dissonâncias ${ }^{10}$.

Em relação ao ensino superior brasileiro no qual esses estudantes estão situados, cumpre destacar que, desde os anos 2000, houve uma grande expansão do sistema, incluindo uma parcela importante de brasileiros que antes sequer imaginariam chegar a essa etapa de ensino (Sampaio et al., 2019; Macedo, 2019). Em 1995, eram 1,7 milhões de matrículas, número que alcançou a marca de 8,4 milhões em 2018. Se tal processo representou uma importante democratização do ensino superior no país, especialmente para estudantes negros e de baixa renda ${ }^{11}$, ocorreu em paralelo um processo inédito de mercantilização e privatização da educação, de modo que o setor privado passou a ser responsável por grande parte das matrículas, atingindo $75 \%$ em 2018 (Brasil, 2018).O setor privado vem crescendo em parte por interesse do mercado em absorver a demanda de estudantes que não conseguem ingressar em universidades públicas ou privadas confessionais, em parte subsidiado pelo governo federal, especialmente alavancados por políticas como o Programa Universidade para Todos (Prouni) e o Fundo de Financiamento Estudantil (Fies) desde meados dos anos 2000 (Sampaio, 2014; Almeida, 2014). Em meio a esse processo de expansão do ensino superior brasileiro nos anos 2000 e 2010, diversas pesquisas têm focalizado processos similares aos registrados neste artigo, a saber, transformações no campo de possibilidades de estudantes de segmentos populares em relação ao ensino superior, também enfatizando transformações ligadas aos marcadores raciais e de gênero. Destaco tanto alguns trabalhos recentes que focalizam as políticas e transformações no perfil estudantil ligadas ao setor privado (Almeida, 2014; Abdal; Navarra, 2014; Milanez, 2016; Costa, 2019), bem como pesquisas voltadas aos novos estudantes de universidades públicas (Figueiredo, 2018; Lima, 2020).

Nesse contexto, em diálogo mais estreito com a perspectiva antropológica, meu olhar destacou a experiência de mulheres jovens e adultas, mas também de homens, que ingressaram no ensino superior 
nesse período, focalizando especialmente uma fração de classe que recentemente esteve no centro do debate brasileiro sobre classes sociais, ficando conhecida como nova classe trabalhadora, nova classe média ou, pela linguagem economicista de mercado, classe C (Kopper; Damo, 2018). Contudo, de minha parte, essas disputas classificatórias também foram objeto de análise (Macedo, 2020). Não utilizei a priori qualquer critério socioeconômico para delimitar quem faria ou não parte da pesquisa de campo. O interesse recaiu justamente nas narrativas cotidianas sobre marcadores sociais da diferença, gênero e classe social em especial, observando o modo como tais categorizações eram negociadas no cotidiano de tais estudantes, orientando ou não suas escolhas.

Com a crise socioeconômica e política que impactou o país a partir de 2015, resultando na estagnação das matrículas no setor privado de educação superior (Brasil, 2018), as perspectivas para o mercado de trabalho pioraram e o desemprego aumentou, complexificando a análise. Tratou-se, assim, do desafio de realizar pesquisa etnográfica que, seguindo a perspectiva de Paul Willis, "[...] reconhece e grava o modo como a experiência é entrelaçada no fluxo da história contemporânea” (Willis; Trondman, 2008, p. 212).

Tendo essa configuração recente como referência, as conversas e entrevistas realizadas com as/os estudantes abordaram principalmente três processos de escolha: a escolha de fazer ensino superior, a escolha por um determinado curso e a escolha por uma instituição de ensino. Para tanto, as trajetórias de vida (escolar, familiar, de trabalho etc.) e as expectativas futuras (qualificação profissional, trabalho, mobilidade social, sonhos, projetos) constituíram-se como dimensões fundamentais para compreender narrativas sobre escolhas, dilemas e perspectivas de futuro.

É importante, também, esclarecer a perspectiva dos marcadores sociais da diferença em articulação aqui mobilizada. Mais do que constatar a importância constitutiva de marcadores sociais como gênero, classe social ou raça, trata-se da aposta de compreensão dessas categorias como estando sempre imbricadas (Davis, 2016; McClintock, 2010). Nessa direção, podemos definir marcadores sociais como "[...] uma maneira de designar como diferenças são socialmente instituídas e podem conter implicações em termos de hierarquia, assimetria, discriminação e desigualdade" (Saggese et al., 2018, p. 19). No entanto, mais do que trabalhar com categorias prontas, trata-se da aposta teórico-metodológica de apreender no cotidiano como tais categorias são produzidas e negociadas (Brah; Phoenix, 2004).

Ao conversar com estudantes universitários ao longo da pesquisa, diversos dilemas se evidenciaram no que se refere à escolha do curso e da instituição para ingresso no ensino superior. Assim, trago a seguir narrativas e experiências de quatro estudantes calouros que tinham passado recentemente pelo processo de ingresso no ensino superior e já estavam matriculados no primeiro semestre de seus cursos. Seguindo uma narrativa mais etnográfica, esses quatro casos foram selecionados 
para o artigo pois tais estudantes compartilhavam experiências próximas, tanto em relação ao curso como em relação à faculdade. Essa aproximação, acredito, permite um olhar mais aproximado sobre os meandros do processo de escolha e dos dilemas enfrentados para ingresso no ensino superior ${ }^{12}$. Em comum, além das experiências iniciais em uma grande instituição privada (no caso dos três jovens apresentados), os estudantes universitários eram a primeira geração de suas famílias a cursar ensino superior (Dumais; Ward, 2010) ${ }^{13}$ e já trabalhavam desde antes de nele ingressar.

\section{Deixar o ‘Sonho’ para Depois: dilemas de Janaína e Henrique}

Conheci Janaína por meio das redes sociais. Sem saber bem por onde começar a conversa com estudantes de Administração da Faculdade Centro, decidi iniciar uma busca em meu celular. Sentada em um banco na porta da Faculdade, entrei em uma rede social e comecei a olhar as fotos postadas no aplicativo que utilizavam aquela geolocalização. Foi assim que encontrei uma foto de Janaína, registrada naquele local, posando para uma fotografia do tipo selfie, contente em suas primeiras semanas de aula, com seus novos colegas, utilizando como legenda da foto a hashtag \#ADM e emojis $^{14}$ de carinhas felizes e corações. Nesse momento, escrevi uma mensagem para Janaína, através desse aplicativo, contando de minha pesquisa universitária e da minha presença no local. Rapidamente tive retorno.

Por meio dessa conversa online, marcamos um primeiro encontro para a semana seguinte em lanchonete próxima, oportunidade em que conheci alguns dos seus colegas, que também se tornariam interlocutores da pesquisa, especialmente Mariana e Henrique. Nessa primeira conversa, marcada para as $18 \mathrm{~h}$ de uma quinta-feira do mês de abril de 2018, Janaína tinha acabado de sair do trabalho, teríamos então uma hora para conversar antes de ela entrar para a aula. Com 20 anos, vestida com calça social e camisa branca, além de um colar com crucifixo no pescoço (ela era da Juventude Católica), Janaína logo me contou que desde os 15 anos, após a morte de seu pai, grande parte da responsabilidade da casa passou para ela. Com três irmãos mais novos, e a mãe de profissão dona-de-casa, coube a Janaína - na posição de filha mais velha - arcar com grande parte das despesas da casa, tornando-se arrimo de família. Desde então, além de uma reduzida pensão que a mãe recebia, era ela quem financiava boa parte das despesas familiares.

Aos 15 anos, diante dessa situação liminar desencadeada pela morte do pai, Janaína empregou-se como vendedora em uma loja de roupas em seu bairro, local que trabalhou por dois anos. Aos 17 anos, conseguiu um novo emprego, dessa vez como Jovem Aprendiz ${ }^{15}$, ingressando na área administrativa de uma empresa de peças automotivas, para trabalhar com faturamento. Ela estava nesse emprego até aquele momento, e trabalhava de segunda a sexta-feira, das 8h45 às 18h25. Moradora do bairro Grajaú, na extrema zona sul da cidade de São Paulo, ela diariamente gastava em torno de duas horas para fazer o deslocamento 
entre sua casa e o trabalho, motivo pelo qual tinha de sair de casa às 5 h30 da manhã. No fim do expediente, saia às 18 h25 e ia a pé para a faculdade, chegando bem próximo do horário de início das aulas, às $19 \mathrm{~h}$. Segundo Janaína, quando a aula terminava depois das $22 \mathrm{~h}$ (o que seria o horário normal do período noturno), ela só chegava em casa por volta de meia-noite. Como é nesse horário que ela ainda tinha que tomar banho, jantar e organizar a roupa social de trabalho do dia seguinte, acabava indo dormir por volta de uma hora da manhã. Assim, entre risos e lamentos, Janaína contava que cotidianamente dormia apenas cerca de quatro horas e trinta minutos.

Nessa mesma ocasião, Janaína contou que desde adolescente seu verdadeiro sonho era fazer Psicologia. Diante da clássica pergunta o que você vai ser quando crescer?, Janaína sempre se sonhou como psicóloga. Em especial, se imaginava trabalhando em um hospital, dando atendimento psicológico para pessoas doentes. Contou-me que no ano anterior, ela chegara a cursar um semestre de Psicologia em outra faculdade privada, mas logo percebeu que aquele curso não daria pra ela: além do preço da mensalidade ser mais alto (com desconto, na outra instituição, ela pagava cerca de R $\$ 600$; já na Faculdade Centro, cursando Administração, ela conseguira uma bolsa, pagando $\mathrm{R} \$ 228$ por mês no primeiro semestre de 2018), o curso exigia muito em termos de horários e estudos, impossibilitando sua dedicação em período integral ao trabalho. Conversando com outros colegas e pesquisando na internet, percebeu ainda que Psicologia seria uma área de retorno lento, mais adequada para quem tem ajuda de família, aquilo não era para ela, não naquele momento atribulado de sua vida. Desde que seu pai morreu - ela enfatizou isso diversas vezes - ficou ciente de que suas escolhas não teriam que ser tomadas a partir dela própria, mas da responsabilidade de levar dinheiro para casa.

Frente a tais dilemas, Janaína optou por trancar o curso de Psicologia e transferir-se para o curso de Administração na Faculdade Centro: "No fim eu acabei escolhendo Administração por ser um curso mais prático. É o que meu chefe me falava desde o começo". Diante de tais pressões, Janaína acabou aceitando que um curso de Administração noturno seria mais condizente com sua situação atual de trabalhadoraestudante, em que trabalhar era condição indispensável para estudar (Comin; Barbosa, 2011), especialmente porque era ela quem pagava a mensalidade. Nessa lógica, com maior brevidade que na área de Psicologia, o curso de Administração lhe permitiria ter um diploma de ensino superior, além de garantir maior empregabilidade e retorno salarial no curto prazo.

Embora sentisse saudades do curso de Psicologia ("quem sabe um dia?"), Janaína contou que seu verdadeiro sonho era ter um diploma de ensino superior, de modo que a escolha do curso até ficaria em segundo plano. Ao acompanhá-la nas redes sociais, vez ou outra apareciam imagens de nostalgia sobre a área sonhada na adolescência, com fotos do curso de psicologia acompanhados da palavra saudade. Para Janaína, entretanto, mais importante do que seguir em uma área específica, “[...] 
hoje em dia o mais importante é ter um diploma, já virou o básico", conforme refletia nessa conversa. Nesse sentido, contou como, no seu trabalho, quando abria alguma nova vaga de emprego, o setor de Recursos Humanos sequer chamava para entrevista quem não estava cursando ou já tinha diploma de nível superior. Diante das exigências de um mercado de trabalho que requeria cada vez mais qualificação, o diploma em Administração, a seu ver, lhe abriria um bom leque, oferecendo possibilidades bastante diversas de inserção profissional em empresas.

Ao refletir ainda sobre sua trajetória escolar, Janaína lembrou sua experiência em diferentes escolas públicas na zona sul da capital. Durante o Ensino Médio, embora se esforçasse para ser boa aluna, a conciliação com o trabalho em período integral, ao lado de grande dedicação à Igreja Católica, tornava o tempo para estudar escasso. Já no final do Ensino Médio prestou o ENEM algumas vezes, sem muito sucesso: "[...] eu vi que eu teria que ter estudado muito mais do que estudei. E se fosse querer uma bolsa do Prouni, eu teria que ter estudado mais ainda. Onde eu arrumo tempo? Não dava para mim, aqui [na Faculdade Centro] foi mais prático". Essa visão da praticidade em relação ao ingresso nas universidades privadas não confessionais, conforme ficou evidente em outras conversas que tive ao longo da pesquisa, refere-se especialmente à simplicidade do vestibular, em geral apenas uma redação, marcada para qualquer dia e horário da preferência do cliente.

Autoclassificada como branca e de classe média, nessa conversa, Janaína contou que tinha consciência de como sua situação social e econômica estava longe dos privilegiados da elite brasileira, mas tampouco era dramática, especialmente porque tinha o que considerava um bom emprego. Além do mais, ela estava indo muito mais longe nos estudos do que seus familiares: seu pai tinha estudado até a $4^{\text {a }}$ série do ensino fundamental; já sua mãe completara o ensino médio, mas como teve quatro filhos, não pôde trabalhar fora. Sua trajetória, assim, já era diferente, e ela valorizava isso, construindo uma narrativa de exaltação do próprio esforço. E Janaína atribuía isso, tanto a seu próprio mérito, como a uma mudança geracional mais ampla ocorrida no Brasil dos anos 2000, que democratizou o acesso à educação: “[...] minha mãe nem se quisesse não podia estudar porque tinha que cuidar dos irmãos, antigamente era tudo mais difícil". De todo modo, vale lembrar que ela, sendo a irmã mais velha, também teve que cuidar dos irmãos. Ainda assim, conseguia naquele momento trabalhar fora e manter a qualificação via educação como uma prioridade em sua vida.

Nesse ponto, a narrativa de Janaína se aproximava de seu colega de sala Henrique, com quem conversei na semana seguinte: segundo ele, uma das grandes vantagens do curso de Administração na Faculdade Centro é que era um curso de custo mais acessível, além de abrir muitas oportunidades de trabalho. Com apenas 18 anos, Henrique (também solteiro, sem filhos, morando com os pais e irmãos) contou que, assim como Janaína, começou a trabalhar cedo: no seu caso, aos 12 anos de idade, no salão de cabelereiros de uma vizinha, na região de Diadema (Grande São Paulo). Conciliou este emprego com a escola por quatro 
anos. Aos 17 anos, começando a refletir sobre ensino superior, passou a sonhar em cursar Medicina, projeto que logo teve o apoio e a animação dos pais. No entanto, rapidamente veio o balde de água fria: cursar medicina na faculdade que ele fora visitar com a mãe custava $\mathrm{R} \$ 6.900$ reais na época, em 2017. Verificaram então o preço de outros cursos da área de Saúde como Odontologia, Fisioterapia e Enfermagem, todos considerados caros. Administração, por ser um dos cursos mais baratos oferecidos naquela outra instituição, acabou por chamar mais a atenção, segundo ele. "Na verdade, eu sempre quis trabalhar em escritório", contou-me depois Henrique, expressando ainda algumas dúvidas sobre tais escolhas. Negociando com tais possibilidades, Henrique passou a contar que desde criança sonhava com algum emprego em que pudesse vestir-se socialmente, além de ter alguma estabilidade. Aqui, assim como em outros casos verificados na pesquisa, o status associado a certas formas de vestimenta eram atrativos para o trabalho em escritório, associado a ocupações mais qualificadas, garantindo o afastamento do trabalho não qualificado ou manual, tão desvalorizado no Brasil, já que pejorativamente associado às classes trabalhadoras. Conforme buscou esclarecer Henrique para mim durante entrevista: "Minha meta mesmo é fazer ensino superior. Um dia, quem sabe, daí eu posso cursar Medicina ou Fisioterapia como hobbie".

Pela pesquisa realizada e conversas que tive ao longo da pesquisa, parece-me que tais narrativas sobre a versatilidade do curso de Administração são bastante frequentes, ainda que dificilmente seja a profissão dos sonhos, realidade nas narrativas tanto de Henrique como de Janaína. Nessa perspectiva, o curso de Administração frequentemente é visto como uma opção que abre muitas portas e que garante maior empregabilidade. Entretanto, também é frequentemente associado à escolha dos indecisos. Ainda assim, por ser um curso fortemente ligado ao empreendedorismo, torna-se atrativo diante da centralidade que tal ideal desempenha na ideologia contemporânea (Boltanski; Chiapello, 2009). Não à toa, o curso está há dez anos listado entre os três maiores cursos de ensino superior do país, conforme dados do censo de Ensino Superior, e, em 2017, concentrava mais de 682 mil estudantes matriculados (Inep, 2017).

Retornando ao caso de Janaína, embora seu verdadeiro sonho de emprego fosse ser psicóloga hospitalar, o mais importante, segundo ela, era ter trabalho, a área tornava-se secundária nesse sentido. Assim, ao refletir sobre suas expectativas futuras, Janaína contou que gostaria de ficar mais alguns anos na empresa em que trabalhava, crescendo na carreira: "[...] eu queria ficar lá uns 4 anos... eu não penso em ficar 12 anos na mesma empresa não. A gente tem que crescer, e para isso ir mudando de experiência também é importante", indicando expectativas de flexibilidade alinhadas com o período histórico atual (Boltanski; Chiapello, 2009).

Entre seus sonhos para os próximos anos, estavam viajar pela primeira vez para o exterior e também, um dia, comprar uma casa própria. Já Henrique considerava que seu maior sonho seria ajudar os pais e ter 
uma vida estável. Ele próprio reconhecia que sua maior preocupação, na verdade, seria atender às expectativas que os pais colocaram nele enquanto bom aluno que acessava pela primeira vez na família o ensino superior. Assim, apoio e cobrança vinham na mesma moeda: "Meu pai cobra muito. Ele apoia, mas cobra".

Entre tais desafios, e diante de um cenário nacional marcado pelas incertezas políticas e econômicas, além de elevados índices de desemprego - no período dessas conversas, no primeiro semestre de 2018, a taxa de desemprego era de 12,6\% entre a população geral e $26,6 \%$ entre os jovens ${ }^{16}$-, Janaína e Henrique seguiam adiante, entre o esforço e a preocupação. Desse modo, a partir das narrativas de Janaína e de Henrique, delineiam-se uma série de dilemas sobre as escolhas nos estudos superiores que, muito além de vocações e aptidões, impõem escolhas pragmáticas, deixando o sonho para depois.

\section{Mãe e Filha Unidas pela Busca do Diploma: dilemas de Mariana e Ana Paula}

Foi através de Janaína que conheci Mariana, também estudante de Administração, período noturno, no primeiro semestre na Faculdade Centro, em 2018. Já sabendo das conversas que Janaína e Henrique haviam tido comigo sobre escolhas no ensino superior, nas semanas anteriores, Mariana concordou em me encontrar na semana seguinte, também às 18 horas, antes do início das aulas, em uma lanchonete próxima à universidade.

Um pouco tímida, Mariana contou que estava com 19 anos e conciliava o primeiro semestre do curso com o trabalho como estagiária no Banco Santander. Para chegar até ali, relatou brevemente sua trajetória educacional e de trabalho: aos 15 anos, através de uma bolsa oferecida pela escola pública em que estudava, na região do bairro Saúde, teve a oportunidade de realizar um curso técnico no SENAI ${ }^{17}$. Na ocasião, podia escolher entre Mecânica, Elétrica e Administração; optou por este último. Por conta desse curso, aos 17 anos teve uma experiência inicial de trabalho no escritório de uma faculdade privada, como Jovem Aprendiz, realizando serviços ligados à área administrativa.

Solteira, autodeclara negra e morando com a mãe, o padrasto e um irmão de 20 anos, Mariana contou que assim que concluiu o Ensino Médio já se programava para ingressar no Ensino Superior. Sempre apoiada por familiares, pela mãe, especialmente, ela ficou em dúvida entre três cursos: Psicologia, Serviço Social ou Enfermagem: "Eu gosto de ajudar, minha principal motivação era essa, eu queria ter um trabalho que eu pudesse ajudar os outros". Entretanto, ao refletir sobre Enfermagem, e em conversas com sua mãe, acabou se dando conta de que não teria estômago para um curso na área da saúde. Psicologia, por outro lado, era visto como um curso caro e que lhe exigiria muita dedicação, dificultando a conciliação com o trabalho, indispensável para arcar com os estudos. Já Serviço Social, por sua vez, era visto como uma área difícil, desvalorizada, talvez também não fosse o curso ideal. 
Nessas conversas com sua mãe, Mariana acabou refletindo sobre duas novas opções de curso, Direito ou Administração: “[...] minha mãe dizia que eu tenho opinião muito forte, sempre fui muito decidida do que é certo ou errado. Acho que ela me imaginava advogada ou administradora". Assim, Mariana passou o ano de 2017 refletindo sobre essas duas possibilidades. Diante das experiências cotidianas no ambiente de trabalho no Banco Santander (primeiro como Jovem Aprendiz, depois como estagiária), percebeu que estava gostando da área, o que a auxiliou a decidir-se pelo curso de Administração.

No final do ano de 2017, já mais certa dessa escolha, Mariana-que é moradora do Bairro Jardim Clímax, zona sul de São Paulo -, passou a pesquisar algumas faculdades na cidade de São Paulo, todas instituições privadas: visitou alguns dos grandes grupos educacionais concorrentes, pesquisou a quantidade de reclamações de cada instituição na internet, leu algumas publicações online como Guia do Estudante e Mundo Vestibular. Entre algumas opções, decidiu-se pela Faculdade Centro pois, além da localização e do preço lhe parecerem propícios, havia recebido recomendações de uma amiga que também estudava naquela IES e gostava.

Mariana lembra que desistiu da tentativa de ingresso em universidade pública porque sempre lhe pareceu ter muita burocracia: vestibulares ou ENEM sempre concorridos, com data marcada, além de um grau de exigência muito alto. Segundo Mariana, faculdades privadas também podem ser boas e são muito mais práticas: "[...] a gente vem, conhece o espaço, pesquisa na internet, se informa pelos sites. Na hora de fazer vestibular é bem mais prático, é só marcar, fazer a redação e pronto. Se precisar de transferência também é mais prático". Tal perspectiva, evidenciada em diversas conversas durante a pesquisa, deve ser sublinhada pois chama a atenção para alguns dos muitos obstáculos ainda presentes no acesso à universidade pública brasileira por estudantes de menor renda. Ao se decidir pela Faculdade Centro, Mariana recebeu uma proposta de bolsa de estudos oferecida pela própria instituição, resultando em uma mensalidade de $\mathrm{R} \$ 380$ mensais para o primeiro semestre, valor mais baixo do que encontrara nas concorrentes.

No geral, Mariana disse estar gostando muito da experiência universitária. O curso de Administração lhe parecia adequado para seus interesses atuais: "[...] é um mercado de trabalho muito amplo; para te falar a verdade eu não estou vendo nenhuma desvantagem nesse curso, só vantagens". Quando concluir, pretendia trabalhar na área administrativa - poderiam ser empresas, escritórios ou mesmo bancos -, mas, se possível, gostaria de conseguir alguma interface com a área de Serviço Social. Era aquele antigo sonho de ajudar os outros que ainda era uma prioridade para Mariana.

Ao refletir sobre sua trajetória familiar (seu pai, com Ensino Fundamental incompleto, trabalhava como taxista; já sua mãe, ensino Médio completo, trabalhava como podóloga), Mariana contou que estava contente com sua entrada no ensino superior, especialmente porque vi- 
via essa experiência juntamente com sua mãe, que também estava cursando essa fase de ensino. Desde nossa primeira conversa, percebia-se como Mariana tinha uma relação bastante forte com a mãe, chamada Ana Paula, não à toa acatou seus conselhos sobre suas afinidades com diferentes opções de curso. Assim, ao falar sobre sua mãe, Mariana contava orgulhosa que era depois de muita luta, aos 43 anos, que ela estava cursando Pedagogia, por meio de um curso à distância em uma universidade pública. Diante de meu interesse em conhecê-la, conversei com Ana Paula alguns dias depois, através de aplicativo de mensagens WhatsApp, que por sorte já estava disposta e animada para contribuir com a pesquisa.

Assim, conheci Ana Paula algumas semanas depois, em abril de 2018, na clínica de podologia onde ela trabalhava, localizada no bairro Jardim Clímax (região da Saúde, Zona Sul de São Paulo), já no fim do seu expediente, por volta de 19 horas. Ela sabia que eu estava interessada em conversar com estudantes universitárias que eram a primeira geração da família a cursar ensino superior, e ficara sabendo por sua filha que eu havia conversado com ela e outros estudantes da Faculdade Centro. Ana Paula logo contou que havia se interessado na pesquisa pois também acreditava no potencial da educação e esperava que histórias como a dela mostrassem a outras pessoas sobre como sempre se pode começar uma nova etapa de estudos, mesmo na fase adulta e com filhos.

Sentadas na sala de podologia em que Ana Paula trabalhava, entre a cadeira branca reclinável e os demais equipamentos clínicos, ela passou a contar em detalhes suas diversas experiências de trabalho, de estudos e familiares. Com 43 anos, iniciou orgulhosa falando sobre as diversas experiências profissionais que já teve ao longo da vida: empregada doméstica, arrumadeira, auxiliar em creche, atendente de bar. Trabalhava como podóloga desde que concluiu o curso Profissionalizante oferecido pelo SENAC, o que já era, segundo ela, uma grande conquista:

Teve um momento da minha vida que entendi o seguinte: se eu não tenho qualificação, tenho só o Ensino Médio, eu vou ser o que daqui a um tempo? Eu não vou querer ficar a vida toda trabalhando em casa de família. Porque arrumadeira não deixa de ser, né? Não vou querer isso para mim até que a morte nos separe! Então o que eu vou fazer da minha vida? Daí começou essa vontade de mudar.

Segundo Ana Paula, o curso profissionalizante foi decisivo para sair do emprego doméstico e começar uma nova trajetória profissional. Lembrou como não aguentava mais trabalhar em casa de família, ocupada com atividades como lavar, passar, cozinhar e arrumar: "[...] quem trabalha como doméstica passa o dia inteiro em pé. Isso é mega cansativo". Conforme já apontei em trabalho anterior (Macedo, 2015), além das atividades desempenhadas - cansativas e desvalorizadas enquanto trabalho considerado não produtivo - o emprego doméstico é uma profissão estigmatizada no Brasil, visto como uma não escolha e mesmo um vestígio do passado escravista do país. No caso de Ana Paula, sua 
mãe também já havia trabalhado como doméstica. Romper com aquele ciclo familiar lhe parecia fundamental:

Eu cresci vendo minha mãe trabalhando nisso, e ela sempre relatava que era difícil. Ela relatava muita humilhação. Indiferença. Ela às vezes não sabia se ia poder comer ou não na casa, então já tomava um café da manhã reforçado antes de sair. Era uma realidade muito difícil... E no meu caso, especialmente no primeiro trabalho, eu e a patroa a gente tinha uma mega distância. Ela me ajudou a conseguir o desconto para o curso, tudo bem, isso foi importante... mas havia uma distância enorme entre o ambiente deles e o ambiente que eu cresci, que eu tenho como meu. A sensação que eu tinha, quando ela olhava pra mim... esse jeito de olhar criava uma barreira enorme. Eu deveria agradar, mas eu me sentia sempre incomodando.

Tais memórias estavam fortemente marcadas em Ana Paula, gerando uma maior emoção nessa parte de nossa conversa. Ela me perguntou se eu já tinha assistido ao filme Histórias Cruzadas (Histórias..., 2011). Eu disse que sim. Lembramos que, encenado pela atriz Viola Davis, a história é sobre três mulheres que trabalham como empregadas domésticas nos anos 1960 nos Estados Unidos, período marcado por violenta segregação racial. Autodeclarada negra, Ana Paula contou que chorou quando assistiu ao filme: "[...] foi nesse filme que eu passei a entender e falei: 'Gente! Essa história de banheiro separado existe faz tempo! É porque elas [as patroas] acham que as negras são sujas, é por isso que a gente também não pode usar o banheiro da dona da casa!'”. Lembrando de como também no Brasil muitas empregadas domésticas só podem usar um banheiro separado, em geral minúsculo e localizado na área de serviço, Ana Paula ainda acrescentou: "[...] eu me vi nessa situação, e eu vi a minha mãe nessa situação".

Cursar o ensino superior, na construção dessa trajetória, tornouse um grande projeto individual. No entanto, essa possibilidade nem sempre esteve no horizonte para Ana Paula. Ela contou que quando terminou o Ensino Médio, o contexto social e político era diferente, constituindo uma realidade bem mais difícil:

Naquela época não tinha certos facilitadores que tem hoje. Hoje tem esses programas para você conseguir bolsa, por exemplo. Naquela época, anos 1990, era muito mais difícil para você estudar. Era difícil dizer assim: 'pai, eu vou fazer faculdade e você vai ter que pagar!'. Éramos duas filhas, de uma família super humilde, não tinha como.

Cursar Pedagogia, no entanto, já era um antigo sonho de infância. Ao menos era assim que Ana Paula reconstruía essa história. Segundo ela, ainda no Primeiro Grau, seu sonho era um dia ser professora e trabalhar na escola em que estudava. No entanto, ao amadurecer, passou a perceber que a profissão também tinha seus riscos e desvantagens:

[...] quando eu vi a falta de respeito com o professor, aquilo me desencantou. Eu não tinha uma segunda opção, mas eu não fui encarar a primeira porque eu vi que era muito complicado. [...]. Não é assim que eu encaro o professor, e não é assim que eu quero ser encarada! E de lá pra cá só piorou o negócio, né? 
Após as diversas experiências profissionais, dois casamentos, maternidade (além de Mariana, Ana Paula é mãe de um rapaz de 20 anos), foi em 2017, por meio de mensagem no celular enviada por uma amiga, que ela viu uma propaganda sobre o Ensino a Distância (EAD) dessa instituição pública, onde eram oferecidas três opções de curso: engenharias, licenciaturas em outras áreas ou Licenciatura em Pedagogia. Ao saber que o curso seria gratuito, conta que seu coração bateu mais forte. "Eu de primeiro fiquei em dúvida se era verdade: tanta notícia falsa hoje em dia, né?". Após uma pesquisa na internet, Ana Paula constatou a veracidade da instituição e se inscreveu para o vestibular. Eram 50 vagas, ficou em 58, na segunda chamada, mas deu certo. Sua felicidade foi enorme: "[...] você imagina? desde 1998 parada, e deu certo! Foi muito bom!". Sobre a modalidade EAD - em grande expansão no Brasil ${ }^{18}$-, Ana Paula conta que no começo achou que seria mais fácil. Especialmente pra quem já trabalhou o dia todo, “[...] exige muita atenção, muita disciplina”. Outro fator negativo é a não integração com colegas de turma, já que se trata de uma modalidade de educação muito solitária, que dificulta a formação de redes de amizades e possíveis contatos profissionais. Ainda assim, Ana estava gostando de aprender sobre políticas educacionais brasileiras como a Lei de Cotas brasileira, implementada em 2012. Aliás, Ana Paula valorizava a política de cotas sociais e raciais, conforme ficou claro em sua narrativa nessa entrevista:

Eu sempre estudei em escola pública, sou negra, então acabei entrando agora na faculdade - não sei se é política de cotas, porque eu disse cor e em que tipo de escola eu estudei, então não deixa de ser cotas, né? Essas políticas facilitam... Eu acabei sendo beneficiada por isso aí, foi um facilitador. Você tem que ter o mesmo mérito dos outros? Tem, mas por conta da desigualdade que a gente vive, essas são políticas necessárias.

Ana Paula e Mariana, ora se aproximavam, ora se afastavam em suas opiniões sobre política, marcadores sociais da diferença e desigualdades. Ainda assim, em ambas as narrativas se expressavam negociações constantes sobre os processos de escolha para ingresso no ensino superior, revelando desafios diversos na empreitada em busca do diploma.

\section{Entre Narrativas Vocacionais e Narrativas Pragmáticas: escolhas possíveis}

Nas narrativas sobre escolhas nos estudos superiores dos quatro estudantes universitários aqui apresentados (Janaína, Henrique, Mariana e Ana Paula), alguns aspectos em comum devem ser destacados: a experiência em escolas públicas, a precedência do trabalho aos estudos superiores, a diferença geracional com mães e pais não diplomados, constituindo-se, em suas famílias, como a primeira geração de estudantes universitários, a moradia em bairros periféricos da cidade de São Paulo, além da experiência de ingressar no ensino superior, compreendida simultaneamente como busca de qualificação profissional e como uma conquista pessoal. 
Uma vez que uma das perguntas principais na condução das entrevistas e conversas realizada para a pesquisa foi sobre como se davam três processos de escolha - escolha por fazer ensino superior, pelo curso e pela instituição -, as narrativas acima apresentadas revelam como tais etapas, no contexto analisado, estão plenamente imbricadas. Momento da vida, preços de mensalidade, sonhos de infância ou juventude, localização da instituição de ensino, oportunidades de bolsas oferecidas por políticas públicas ou privadas, expectativas dos familiares, expansão do ensino superior brasileiro - diversos aspectos se imbricam, revelando múltiplas conexões que delineiam caminhos, de modo que a opção pelo curso aparece articulada à escolha da instituição, e estas se conectam com a decisão mais geral de ingressar no ensino superior, aproveitando as oportunidades oferecidas pelo mercado e por políticas públicas no Brasil dos anos 2010.

De todo modo, considero que o mais importante de tais narrativas a ser destacado é o modo como os estudantes negociavam suas escolhas. Mesmo nos casos em que o curso ou a faculdade dos sonhos se revelaram inacessíveis, a noção de escolha era negociada e valorizada, num esforço de autoafirmação que, acredito, deve ser enfatizado na análise. Se, no passado vivenciado por familiares ou, no caso da juventude de estudantes adultas como Ana Paula, o ensino superior surgia como algo inacessível, e o futuro no mercado de trabalho era visto como um lugar de não escolha, a reivindicação pelo direito de escolher surge destacada aqui nessas narrativas. Assim, critérios como aptidões e gostos, influência de pais e amigos, experiências prévias de trabalho, estilos de vida e mesmo vocações religiosas foram mobilizadas nas narrativas sobre o processo de escolha nos estudos superiores. Ultrapassando a dicotomia comumente associada a noção de escolha - livre ou determinada - tais narrativas revelam o modo como tais processos são tecidos no cotidiano, de modo constante e instável, intercalando limitações e possibilidades, sonhos e frustrações, adaptações e novos arranjos, delineados em uma conjuntura sócio-histórica específica que permitiu esse passo.

Quero ressaltar a importância de se olhar para tais escolhas de maneira matizada, levando simultaneamente em conta as narrativas pragmáticas (facilidade de acesso, oportunidades no mercado de trabalho, localização da faculdade e valor da mensalidade etc.) e as narrativas vocacionais (habilidades, sonhos, imaginários, amor à área, vontade de fazer o bem, entre outras motivações apresentadas) (Macedo, 2019). Cientes de que suas ações e decisões não se deram num mundo de fazde-contas, tal como prega certa visão sobre a livre-escolha comumente mobilizada em testes vocacionais, ainda assim, as narrativas das estudantes buscam dar sentido aos passos realizados em suas diferentes trajetórias.

Focalizando o contexto educacional francês dos anos 1970, em análise que se tornou central nas discussões contemporâneas sobre ciências sociais e educação, Pierre Bourdieu (1998) refletiu como as escolhas do destino em matéria educacional, embora aparecessem aos indivíduos e aos seus familiares como sendo livres ou resultado de dons 
Macedo

naturais, quando focalizadas pela lente sociológica revelavam-se como "[...] interiorização do destino objetivamente determinado" (p. 47). Segundo Bourdieu, “[...] as crianças e sua família se orientam sempre em referência às forças que as determinam. Até mesmo quando suas escolhas lhes parecem obedecer à inspiração irredutível do gosto ou da vocação, elas traem a ação transfigurada das ações objetivas" (1998, p. 49).

Embora reconheça a importância dessa perspectiva, e incorpore parcialmente o referencial teórico bourdiesiano na presente análise, me parece necessário matizar tal determinação quando nos aproximamos de trajetórias individuais. Além dessa forma de análise possivelmente desconsiderar as negociações de sentido que os próprios sujeitos atribuem a esses momentos decisivos, em uma escrita de cunho etnográfico, tais métricas não levariam longe. Aproximo-me, assim, da perspectiva de Paul Willis, que, ao analisar os sentidos atribuídos à vida escolar de jovens ingleses da classe trabalhadora nos anos 1970, concluía: "[...] é demasiado fácil dizer simplesmente que eles não têm escolha" (1991, p. 11). Willis, ao contrário, buscou revelar os múltiplos sentidos e negociações que aqueles jovens realizavam entre suas visões de mundo, a instituição escolar e o posterior trabalho industrial.

Assim, para além de uma perspectiva binária e, de certo modo, reducionista, entre escolhas livres ou determinadas, trata-se aqui justamente do desafio de compreender as nuances e matizes que constituem diferentes sentidos atribuídos a tais processos de escolha, ainda que instáveis, entre a resistência e a resignação, o encantamento e a decepção. Trata-se igualmente do desafio de levar em conta a transformação do campo de possibilidades - tendo em conta a expansão recente do ensino superior no Brasil -, constituindo novos imaginários sobre educação, trabalho e mobilidade social.

Recebido em 28 de julho de 2020 Aprovado em 13 de março de 2021

\section{Notas}

1 Este artigo é parte de pesquisa de doutorado defendida em 2019 no Programa de Pós-Graduação em Antropologia Social da USP, sob orientação de Heloisa Buarque de Almeida e com financiamento CAPES (Macedo, 2019).

2 O Guia do Estudante constituiu-se como a principal publicação sobre orientação vocacional e profissional no Brasil, vendido pela Editora Abril no formato de revistas e, posteriormente, também em formatos online. A primeira publicação é de 1984.

3 Entre tais publicações, destaco a qualidade do Guia Tô no Rumo: jovens e escolha profissional, formulada pela Ação Educativa e voltado especialmente para educadores que trabalham com jovens de escolas públicas (Souza, 2014).

4 Como comparação, vale lembrar que, segundo histórico realizado pela publicação, na primeira edição do Guia, em 1984, foram listadas 83 profissões universitárias. Disponível em: <http://origin.guiadoestudante.abril.com.br/ premio/sobre-premio/conteudo_132818.shtml>. Acesso em: 15 set. 2018.

5 O ENEM - Exame Nacional do Ensino Médio - é a principal avaliação para ingresso no ensino superior brasileiro. Implementado em 1998, passou por

Educação \& Realidade, Porto Alegre, v. 46, n. 3, e105800, 2021. 
algumas transformações nos anos 2000, até em 2010 integrar-se ao SISU - Sistema de Seleção Unificada -, tornando-se a principal porta de entrada para o ensino superior no país. Sobre a expansão do ENEM nos anos 2000 para acesso a diferentes políticas educacionais, com destaque para o Prouni, ver Almeida (2014).

6 Também na pesquisa realizada na Inglaterra por Reay et al (2005), entre os jovens de classe média, a escolha por ingressar no ensino superior surgia como algo tido como evidente, natural. Em oposição, os jovens britânicos das classes trabalhadoras surgiam marcados por dúvidas e ambivalências no processo de decisão de ingresso no ensino superior.

7 A reflexão de Margaret Mead (1973) sobre as escolhas educacionais se dá de modo comparativo, indagando o peso da escolha entre as jovens estadunidenses nos anos 1920, em comparação com as jovens samoanas, leves e descompromissadas, não dilaceradas diante da necessidade frequente de realizar escolhas individuais.

8 O antropólogo Gilberto Velho (2006; 2013), ao longo de sua obra, mobilizou os conceitos de projeto e campo de possibilidades, a partir das reflexões do sociólogo austríaco Alfred Schutz. Segundo Velho, o campo de possibilidades seria a área de manobra que "[...] permite algum exercício de escolha e decisão para os agentes individuais" (Velho, 2006, p. 8). Por sua vez, a investigação dos projetos individuais seria “[...] uma tentativa de perceber como e até que ponto indivíduos podem se organizar para desenvolver condutas específicas para atingir seus objetivos" (Velho, 2006, p. 8).

9 A Faculdade Centro está em uma região central da cidade de São Paulo, próximo a estações de metrô. Concentra, assim, um público mais heterogêneo socialmente do que a Faculdade Bairro, localizada na região de Taboão da Serra/ bairro de Campo Limpo, zona sudoeste da região metropolitana de São Paulo. Se na Faculdade Bairro um dos motivos de escolha da instituição (além do preço e do reconhecimento) era a proximidade com a residência, na Faculdade Centro a proximidade com o trabalho se destacou.

10 Conforme sintetiza Lahire, em contraposição a análises mais unívocas das disposições sociais, como a que seria realizada por Pierre Bourdieu, trata-se da aposta em um olhar mais matizado para os agentes sociais, valorizando contradições e dissonâncias: "Isso não significa que se tenha de privilegiar a contradição em vez da coerência, a heterogeneidade em lugar da homogeneidade, mas apenas se deve evitar permanecer cego e surdo às dissonâncias, às diferenças, às contradições e às heterogeneidades, sempre que elas existirem" (Lahire, 2004, p. 44).

11 Vale lembrar que, desde lei aprovada em 2012, o Brasil possui um sistema nacional de política de cotas, destinando $50 \%$ das vagas de universidades públicas federais para estudantes autoclassificados como negros e estudantes de baixa renda (Telles; Paixão, 2013).

12 As narrativas das estudantes Ana Paula e Mariana, por serem mãe e filha e, assim, evidenciarem transformações que também são geracionais, foram analisadas com maior detalhamento neste artigo do que os dois primeiros casos apresentados, de Janaína e Henrique, seguindo também o fluxo etnográfico da pesquisa de campo realizada.

13 Em artigo intitulado Cultural capital and first generation college success, Dumais e Ward analisam como ser a primeira geração da família a cursar ensino 
Macedo

superior introduz uma série de desafios adicionais aos processos de escolha no ensino superior (Dumais; Ward, 2010).

14 Emojis são uma linguagem de sinais gráficos amplamente utilizada nas redes sociais no período da pesquisa.

15 Jovem Aprendiz ou Aprendiz Legal é um programa para inserção de jovens no mundo do trabalho, baseado na Lei de Aprendizagem (Lei 10.097/2000), que determina que empresas de médio e grande porte contratem jovens de 14 a 24 anos na condição de aprendizes. Informações disponíveis em: <http://site. aprendizlegal.org.br/o-que-e>. Acesso em: 01 jul. 2019. Por ser uma alternativa importante de primeiro emprego em uma cidade como São Paulo, a inserção laboral pelo programa apareceu diversas vezes ao longo da pesquisa.

16 Dados do IBGE, disponíveis em reportagem do portal G1. Disponível em: <https://g1.globo.com/economia/noticia/2018/08/17/desemprego-entre-osjovens-e-superior-ao-dobro-da-taxa-geral-aponta-ibge.ghtml>. Acesso em: 01 nov. 2018.

17 O SENAI - Serviço Nacional de Aprendizagem Industrial -, criado em 1942, é uma instituição privada sem fins lucrativos que oferece, entre outros serviços, cursos de qualificação profissional para jovens.

18 Vale lembrar que os cursos EAD tiveram grande expansão no período recente, crescendo 226\% entre 2007 e 2017, conforme dados do Censo do Ensino Superior de 2017 (Brasil, 2018).

\section{Referências}

ABDAL, Alexandre; NAVARRA, Julia. 'Uni Por Uni, Eu Escolhi a que Era do Lado da Minha Casa': deslocamentos cotidianos e o acesso, a permanência e a fruição da universidade por bolsistas do ProUni no Ensino Superior privado. Novos Estudos CEBRAP, n. 99, p. 65-87, 2014.

ABRIL. Guia do Estudante: profissões - vestibular 2016. São Paulo: Editora Abril, 2016.

ALMEIDA, Wilson. Prouni e o Ensino Superior Privado Lucrativo em São Paulo. São Paulo: Musa Editora, 2014.

BOLTANSKI, Luc; CHIAPELLO, Eve. O Novo Espírito do Capitalismo. São Paulo: Martins Fontes, 2009.

BOURDIEU, Pierre. Escritos de Educação. Petrópolis: Vozes, 1998.

BRAH, Avtar; PHOENIX, Ann. Ain't I a Woman? revisiting intersectionality. Journal of International Women's Studies, Bridgewater, USA, v. 5, n. 3, p. 75-86, 2004.

BRASIL. Ministério da Educação. Censo da Educação Superior 2017: notas estatísticas. Brasília: Instituto Nacional de Estudos e Pesquisas Educacionais, 2018. Disponível em: <http://download.inep.gov.br/educacao_superior/censo_superior/documentos/2018/censo_da_educacao_superior_2017-notas_estatisticas2.pdf>. Acesso em: $20 \mathrm{dez} .2018$.

COMIN, Álvaro e BARBOSA, Rogério. Trabalhar para Estudar: sobre a pertinência da noção de transição escola-trabalho no Brasil. Revista Novos Estudos Cebrap, São Paulo, v. 91, p. 75-95, 2011.

COSTA, Henrique. Mulheres Paulistanas no Prouni: mediações entre a universidade e a precariedade. Mediações-Revista de Ciências Sociais, v. 24, n. 3, p. 213-226, 2019.

Educação \& Realidade, Porto Alegre, v. 46, n. 3, e105800, 2021. 
DAVIS, Angela. Mulher, Raça e Classe. São Paulo: Boitempo, 2016.

DUMAIS, Susan; WARD, Aaryn. Cultural Capital and First-Generation College Success. Poetics, Durham, v. 38, n. 3, p. 245-265, 2010.

FIGUEIREDO, Alice. Limites Para Afiliação À Vida Acadêmica de Estudantes de Camadas Populares no Contexto de Expansão Universitária. Educação e Pesquisa, São Paulo, v. 44, p. 1-18, 2018.

GUSMÃO, Neusa. Antropologia e Educação: origens de um diálogo. Cadernos Cedes, Campinas, v. 18, n. 43, p. 8-25, 1997.

HISTÓRIAS Cruzadas. Direção: Tate Taylor. Produção: Chris Columbus e outros. Intérpretes: Viola Davis; Emma Stone; Octavia Spencer e outros. Roteiro: Tate Taylor. Estados Unidos, 2011. 1 DVD (146 min.).

KOPPER, Moises; DAMO, Arlei. A Emergência e a Evanescência da Nova Classe Média Brasileira. Horizontes Antropológicos, Porto Alegre, ano 24, n. 50, p. 335376, 2018.

LAHIRE, Bernard. Sucesso Escolar nos Meios Populares: as razões do improvável. São Paulo: Editora Ática, 1997.

LAHIRE, Bernard. Retratos Sociológicos: disposições e variações individuais. Porto Alegre: Artmed, 2004.

LIMA, Raquel Guilherme. Para Além do Trânsfuga de Classe: a socialização plural em narrativas da primeira geração de formados no ensino superior. Revista Brasileira de Ciências Sociais, v. 35, n. 104, p. 1-17, 2020.

LINS, Beatriz; PARREIRAS, Carolina; FREITAS, Eliane. Estratégias para Pensar o Digital. Cadernos de Campo (São Paulo - 1991), v. 29, n. 2, p. 1-11, 2020.

MACEDO, Renata Mourão. 'Agora quer ser rica?': negociações cotidianas sobre classe e mobilidade social entre estudantes universitárias. Antropolitica - Revista Contemporânea de Antropologia, n. 50, p. 215-242, 2020.

MACEDO, Renata Mourão. Escolhas Possíveis: narrativas de classe e gênero no ensino superior privado. 2019. $235 \mathrm{f}$. Tese (Doutorado em Antropologia Social) Programa de Pós-Graduação em Antropologia, Universidade de São Paulo, São Paulo, 2019.

MACEDO, Renata Mourão. Trabalhadoras e Consumidoras: transformações do emprego doméstico na sociedade brasileira. Política \& Trabalho, n. 42, p. 311333, 2015.

MCCLINTOCK, Anne. Couro Imperial: raça, sexualidade e gênero no embate colonial. Campinas: Editora Unicamp, 2010.

MEAD, Margaret. Coming of Age in Samoa. New York/USA: Morrow Quill Paperbacks, 1973.

MILANEZ, Gabriel Gustavo. Trajetórias Pós-ProUni: um estudo sobre egressos do Programa Universidade Para Todos na cidade de São Paulo. 2016. 238 f. Dissertação (Mestrado em Sociologia) - Programa de Pós-Graduação em Sociologia, Universidade de São Paulo, São Paulo, 2016.

MISKOLCI, Richard. Sociologia Digital: notas sobre pesquisa na era da conectividade. Revista Contemporânea, São Carlos, v. 6, n. 2, p. 275-297, 2016.

NOGUEIRA, Claudio. Escolha Racional ou Disposições Incorporadas: diferentes referenciais teóricos na análise sociológica do processo de escolha dos estudos superiores. Estudos de Sociologia, Araraquara, v. 2, n. 18, p. 1-20, 2012.

ORTNER, Sherry. New Jersey Dreaming: capital, culture and the class of 58. United States of America: Duke University Press, 2003. 
PEREIRA, Alexandre Barbosa. Outros Ritmos em Escolas da Periferia de São Paulo. Educação \& Realidade, Porto Alegre, v. 41, n. 1, p. 217-237, 2016.

REAY, Diane; DAVID, Miriam; BALL, Stephen. Degrees of Choice: social class, race and gender in higher education. Londres, UK: Trentham Books, 2005.

SAGGESE, Gustavo et al. (Org.). Marcadores Sociais da Diferença: gênero, sexualidade, raça e classe em perspectiva antropológica. São Paulo: Terceiro Nome e Editora Gramma, 2018.

SAMPAIO, Helena et al. Expanding Access to Higher Education and its (Limited) Consequences for Social Inclusion: the brazilian experience. Social Inclusion, Lisboa, v. 7, p. 7- 17, 2019.

SAMPAIO, Helena. O Setor Privado de Ensino Superior no Brasil: continuidades e transformações. Revista Ensino Superior Unicamp, 2014. Disponível em: $<$ https://www.revistaensinosuperior.gr.unicamp.br/artigos/o-setor-privadode-ensino-superior-no-brasil-continuidades-e-transformacoes $>$. Acesso em: 03 mar. 2020

SETTON, Maria da Graça. Socialização e Individuação: a busca pelo reconhecimento e a escolha pela educação. São Paulo: AnnaBlume, 2016.

SOUZA, Raquel. Guia Tô no rumo: jovens e a escolha profissional. São Paulo: Ação Educativa, 2014

STRATHERN, Marylin. Parentesco por Iniciativa: a possibilidade de escolha dos consumidores e as novas tecnologias de reprodução. Análise Social, Lisboa, V.XXVI, p. 1011-1022, 1991.

TELLES, Edward; PAIXAO, Marcelo. Affirmative Action in Brazil. LASA forum, Pittsburgh, v. 44. n. 2, p. 10-11, 2013.

VARGAS, Hustana. Sem Perder a Majestade: profissões imperiais no Brasil. Estudos de Sociologia, Araraquara, v. 15, n. 28, p. 107-124, 2010.

VELHO, Gilberto. Ciências Sociais e Biografia Individual. Revista Estudos Históricos, n. 38, p. 3-9, 2006.

VELHO, Gilberto. Um Antropólogo na Cidade. Rio de Janeiro: Zahar, 2013.

WILLIS, Paul. Aprendendo a Ser Trabalhador: escola, resistência e reprodução social. Porto Alegre: Ed. Artes Médicas, 1991.

WILLIS, Paul; TRONDMAN, Mats. Manifesto pela Etnografia. Revista Educação, Sociedade e Culturas, Porto, v. 27, p. 211-220, 2008.

Renata Mourão Macedo é pesquisadora de pós-doutorado na Faculdade de Educação da Universidade de São Paulo (USP) e Doutora em Antropologia Social pela USP.

ORCID: http://orcid.org/0000-0002-2807-4605

E-mail: renatagmourao@hotmail.com

Editora-Responsável: Carla Vasques

Este é um artigo de acesso aberto distribuído sob os termos de uma Licença Creative Commons Atribuição 4.0 Internacional. Disponível em: <http:// creativecommons.org/licenses/by/4.0>. 